Carlos Mário da Silva Velloso. Ministro do Tribunal Federal de Recursos, professor na Universidade de Brasília- UnB.
Carlos Mário da Silva Velloso

\title{
Do Poder regulamentar
}

\section{O Regulamento: conceito}

Os regulamentos, na precisa definição de Oswaldo Aranha Bandeira de Melo, "são regras jurídicas gerais, abstratas, impessoais, em desenvolvimento da lei, referentes à organização e ação do Estado, enquanto poder público" (Princlpios gerais de direito administrativo, Forense, 2. ed., 1/342). Editados pelo Poder Executivo, visam a tornar efetivo o cumprimento da lei, propiciando facilidades para que a lei seja fielmente executada. É que as leis "devem, segundo a melhor técnica, ser redigidas em termos gerais, não só para abranger a totalidade das relações que nelas incidem, senão, também, para poderem ser aplicadas, com flexibilidade correspondente, às mutações de fato das quais estas mesmas relações resultam." (Vicente Ráo, O Direito e a vida dos direitos, Ed. Res. Universitária, São Paulo, 1976, p. 266). Por isso, as leis não devem descer a detalhes, mas, conforme acima ficou expresso, conter, apenas, regras gerais. Os regulamentos, estes sim, é que serão detalhistas. Bem por isso, leciona Esmein, são eles "prescrições práticas que têm por fim preparar a execução das leis, completando-as em seus detalhes, sem lhes alterar, todavia, nem o texto, nem o espirito." (Elém. de droit const., p. 536, ap. Vicente Ráo, ob. cit., p. 267).

\section{Regulamento e lei: distinção}

Para Hauriou, o regulamento distingue-se da lei pelo seu conteúdo, vale dizer, há uma matéria própria da lei e uma matéria específica do regulamento $(\mathrm{M}$. Hauriou, Précis de droit administratif et de droit public, Paris, 1914, p. 54). Victor Nunes leal, que escreveu trabalho clássico a respeito do assunto (Lei e regulamento, RDA, $1 / 371$; in Problemas de dir. público, Forense, 1960, p. 57), diverge dessa orientação, ao afirmar que os critérios de Hauriou não são precisos e que "sua argumentação visa sobretudo à demonstração de que o regulamento é ato administrativo e não ato legislativo, tendo em vista principalmente que, na França, os órgãos judicantes não podem declarar a inconstitucionalidade das leis, mas podem deixar 
de aplicar os regulamentos eivados de excesso de poder ou de ilegalidade." Para Victor Nunes Leal, o critério formal de distinção entre lei e regulamento é muito mais seguro, critério que se estabelece a partir da distinção feita por Duguit, entre o ponto de vista formal e o substancial para qualificação dos regulamentos. O regulamento, para Duguit, é lei em sentido material, desde que contenha as características da lei. Sob o ponto de vista formal, entretanto, diferem: o regulamento é ato administrativo subordinado à lei. Porque, segundo Duguit, "au point de vue formel, est loi tout décision émanée de l'organe qui, d'après la constitution du pays consideré, a le caractère d'organe législatif." "Au point de vue matériel, la loi est l'acte par lequel l'Etat formule une règle de droit objectif ou crée des règles, organise des institutions destinées à assurer la mise en oeuvre d'une règle de droit objectif." (Léon Duguit, Traité de droit constit., Paris, 3. ed., II/161 e 165). Dai a conclusão de Duguit: "Au point de vue matériel, est loi tout acte qui possède en soi la caractère intrinsèque de loi, et cela indépendament de l'individu ou du corps qui fait l'acte." (ob. e loc. cits., p. 161). Assestando bateria contra o entendimento de Hauriou, que teria se enganado, segundo Duguit, escreve este: "Hauriou dit que la loi doit être définie au point de vue de sa matière en opposition avec le règlement. Je crois que sur ce point Hauriou se trompe, et j'espère montrer qu'iln'y a point de différence matérielle entre la loi et le règlement (cf. § 20)." (ob. e loc. cits., p. 164). Na esteira do entendimento do doyen da Faculdade de Direito da Universidade de Bordeaux, é perfeita, sob todos os aspectos, a lição de Victor Nunes Leal: "A distinção entre o critério formal e o critério material é fértil para o jurista, porque a hieraquia existente entre lei e regulamento, assim como entre constituição e lei, é só de natureza formal. Para que o regulamento seja invalidado é preciso que contrarie disposições de uma lei formal; para que as lei deixem de ser aplicadas é necessário que ofendam disposições do texto constitucional." (ob. cit.). Em síntese, pois, o regulamento, porque é editado pelo Poder Executivo, é ato administrativo, sob o ponto de vista formal; todavia, porque apresenta as características da lei - regra geral, abstrata, obrigatória - élei em sentido material.

\section{A Teoria dos atosnormativos}

Para Manoel Gonçalves Ferreira Filho, comentando o processo legislativo contido na Constituição brasileira, artigo 46, ao constituinte faltou visão sistemática dos atos normativos. Essa sistematização deve assentar-se na distinção entre atos normativos gerais e individuais, a partir do conceito de norma formulado por Kelsen. Escreve o professor paulista: "se norma é o sentido de um ato através do qual uma conduta é prescrita, permitida ou, especialmente, facultada, no sentido de adjudicada à competência", como ensina Kelsen, não é incorreto distinguir entre as normas gerais que prescrevem conduta a pessoas indiscriminadas que possam estar numa mesma situação, e normas individuais que prescrevem conduta a pessoa, ou pessoas discriminadas." (Curso de Dir. Const., Saraiva, 1976, 6 a ed., p. 179). Nessa ordem de idéias, a Constituição seria ato normativo 'inicial'; seguem-se os atos normativos 'derivados', que são as emendas constitucionais e, nos Estados federais, as consti- 
tuições estaduais. Derivados, ainda da Constituição e só a esta subordinados, estão os atos normativos 'primários', que podem ser gerais e particulares. No sistema constitucional brasileiro, são atos normativos primários gerais: a lei (ordinária e complementar), o decreto-lei e a lei-delegada. Esão atos normativos primários particulares: o decreto-legislativo e a resolução legislativa. Num segundo plano, estão os atos normativos secundários, que estão subordinados aos atos primários. Esses atos normativos secundários também podem ser gerais e particulares. São gerais: os regulamentos; e são particulares: os atos administrativos e jurisdicionais, stricto sensu. Por ato normativo, pois, pode-se conceber o ato legislativo, formalmente e/ou materialmente considerado, ou o ato administrativo com o sentido de lei material, isto é, que enuncia uma norma jurídica (regra jurídica), ou um preceito de direito, ou que explica o sentido do seu conteúdo, marcado de imperatividade e generalidade, assim estabelecendo forma de conduta a pessoas indiscriminadas ou discriminadas.

\section{O Regulamento como ato normativo secundário}

O regulamento é, pois, de regra, um ato normativo secundário geral. Assim o é, no sistema constitucional brasileiro. Por ser secundário, não pode o Executivo, ao exercer a função regulamentar. criar direitos ou obrigações novas, ou, numa palavra, inovar na ordem jurídica, já prelecionava Pimenta Bueno (Dir. públic. brasil., p. 236 e segs.). Em síntese magnífica do pensamento de eminentes doutrinadores, escreveu V. Ráo: "os regulamentos constituem legislação secundária (Roubier, Les conflits des lois, n. 4; Messineo, Man. dir. civ. e com., voll, no 9; Bielsa, Trat. - 3ed., I/287; Zanobini, Corso dir. amm., vol. I, n. 6, p. 70), assim revelando uma força específica reflexa e derivada da lei (Massari, in Diz. dir. priv., Scialoja vb. Legislazionel cujo objeto consiste em desenvolver, facilitandoIhes a execução, os princípios fixados pela lei (Messineo, loc. citado), atuando intra legem (Massari, loc. cit.; Stolfi, Dir. civ., vol. I, n. 231; Azzariti, Dir. civ. ital., vol. I, n. 24), sem poder alterá-la por qualquer modo (Beviláqua, Teoria geral do dir. civil, 1908, p. 14, etc)." (Vicente Ráo, ob. eloc. cits. p. 269).

A democracia liberal proclama, como dogma, a separação dos poderes. E porque cabe ao Legislativo, na doutrina de Montesquieu, fazer a lei, o regulamento, ato normativo secundário, obra do Executivo, deve submeter-se à lei sob três aspectos, na lição de G. Vedel: "1.) deve ser editado sob as formas previstas pela lei; $2^{\circ}$.) não pode abranger senão matérias não legislativas, isto é, que não foram reservadas à lei, tomadas pelo legislador; $3^{\circ}$ ) o regulamento não pode contradizer a lei." ICours de droit const., Paris, 1958/1959, p. 973; ap. Manoel Gonçalves Ferreira Filho, A Autonomia do poder regulamentar na Constituição francesa de 1958, RDA, 84/24).

\section{Classificação dos regulamentos}

Os regulamentos podem ser: a) de execução, que têm por finalidade a aplicação das leis; b) autônomos, que se subdividem em duas classes: b.1) externos, que contêm normas dirigidas aos cida- 
dãos de modo geral; b.2) internos, que dizem respeito à organização, competência e funcionamento da Administração Pública. Essa classificação foi adotada pelo direito italiano (Lei de 31.01.26), que acrescentou os regulamentos delegados (Raneletti, Principii, 1/263/266; Themístocles B. Cavalcanti, Trat. dir. adm. 1/308; Santi Romano, Corso, p. 66; Cino Vitta, Dir. amm., p. 45).

Com pequena variação, a classificação de Oswaldo Aranha Bandeira de Melo: a) regulamentos executivos, ou de execução; b) autorizados ou delegados; c) independentes ou autônomos.

Regulamentos executivos ou de execução - São os que desenvolvem os textos legais, constituindo os seus preceitos "regras técnicas de boa execução da lei, para sua melhor aplicação". 10. A. Bandeira de Mello, ob. cit., I/352). Esse regulamento simplesmente complementa os preceitos da lei. É o regulamento brasileiro (Constituição Federal, artigo 81, III).

Regulamentos independentes ou autônomos - Têm força de lei. Certos sistemas constitucionais conferem ao Poder Executivo o poder de legislar sobre determinados assuntos. Enfeixam, os regulamentos autônomos, "faculdade regulamentar praeter legem e mesmo contra legem para regular qualquer matéria que constitucionalmente não tenha sido reservada aos órgãos legislativos, pertinentes às relações do Estado-poder com terceiros." (O. A. Bandeira de Mello, ob. cit. , 1/343). Subdividem-se em b. 1) orgânicos; b.2) regimentais; b.3) policiais. Os orgânicos e regimentais denominam-se regulamentos independentes internos; os policiais, externos.

Regulamentos autorizados ou delegados - O Executivo os edita "em razão de habilitação legislativa, que lhe é conferida pelo Legislativo, porém nos termos dessa determinação de competência, para desenvolver os preceitos constantes da lei de habilitação, que delimita o seu âmbito a respeito." (O. A. Bandeira de Mello, ob.
cit., 1/346).

Em tais regulamentos, o Executivo simplesmente completa os contornos da lei, sem, todavia, inovar com caráter inicial na ordem jurídica. "Uma coisa é delegar o poder de legislar sobre o direito educacional", exemplifica O. A. Bandeira de Mello, "e outra habilitar o Executivo a regulamentar texto de lei, em que se fixam as diretrizes a respeito. Ao levar a efeito essa delegação o faz na conformidade da matéria demarcada no texto legal." (ob. cit., p. 347). Em sistemas constitucionais que impedem a delegação de poderes, como no caso brasileiro, em que essa delegação é proibida, ressalvadas as exceções constitucionais (C.F., art. 6\% , parág. único), o assunto deve ser encarado com a maior cautela. No regulamento delegado o Executivo recebe delegação para apreciação de fatos em razão dos quais resultariam, nos termos da lei, situações jurídicas. Os exemplos formulados por O. A. Bandeira de Mello facilitam o entendimento: "Assim, o Legislativo, ao instituir o tabelamento dos preços de mercadorias, e ao definir as infrações em que incorrem os contraventores, pode incumbir ao Executivo fixar a tabela dos preços máximos das utilidades. Aliás, falta ao legislador elementos para dispor a respeito, pois os preços há de sofrer as flutuações do mercado e de ou- 
tros fatores. Demais, o ato de fixar as tabelas nada tem de legislativo. Ao contrário, constitui ato concreto, específico." ..."Igual consideração cabe com referência à lei de zoneamento urbano. Ela distingue as zonas em residenciais, de uma só residência, e de prédios de apartamentos, industriais e comerciais, e mistas. Contudo, ao Executivo cabe declarar tal rua como residencial ou industrial, tendo em vista o conceito legal desses tipos de vias públicas." (ob. cit. , ps. 347/348).

\section{Oregulamento na Constituição da França de 1958}

O poder regulamentar adquire, na Constituição da França, que foi adotada no referendum de 28 de setembro de 1958 e promulgada em 4 de outubro do mesmo ano, notável expressão, o que é ressaltado em trabalho doutrinário do Professor Manoel Gonçalves Ferreira Filho (A Autonomia do poder regulamentar na Constituição francesa de 1958, RDA, 84/24; Idem, Do Processo legislativo, Saraiva, 1968, ps. 145 e segs, ). É que a Constituição francesa enumera, no artigo 34, as matérias que devem ser objeto de leis, de leis orgânicas, de leis de programação e de leis de princípios fundamentias, estabelecendo, no artigo 37, que as matérias fora do domínio da lei terão caráter regulamentar e que "os textos de forma legislativa referentes a tais matérias poderão ser modificados por decretos promulgados após ordem do Conselho de Estado" e que "os textos legislativos, que vierem a ser aprovados depois de entrada em vigor a presente Constituição, só poderão ser modificados por decreto se o Conselho Constitucional declarar que têm caráter regulamentar, conforme definição do parágrafo precedente." Ademais, pode o Parlamento, a respeito da matéria própria da lei (art. 34), delegar ao Governo (Executivo) poderes para legislar através de portarias. Vale a transcrição:

"Article 38. Le Gouvernement peut, pour l'exécution de son programme, demander au Parlement l'autorisation de prendre par ordonnances, pendant un délai limité, des mesures qui sont normalement du domaine de la loi.

Les ordonnances sont prises en Conseil des Ministres après du Conseil d'Etat. Elles entrent en vigueur dès leur publication mais deviennent caduques si le projet de loi de ratification n'est pas déposé devant le Parlement avant la date fixée par la loid'habilitation.

A l'expiration du délai mentionné au premier alinéa du présent article, les ordonnances ne peuvent être modifiées que par la loi dans les matières quisont du domaine législatif ".

Segundo o art. 34, a lei estabelecerá as regras concernentes: "aos direitos civis e às garantias fundamentais concedidas aos cidadãos para o exercício das liberdades públicas; às obrigações impostas pela defesa nacional aos cidadãos quanto à sua pessoa e seus bens; à nacionalidade, ao estado e à capacidade das pessoas, aos regimes matrimoniais, às sucessões e doações; à determinação dos delitos e faltas ao mesmo tempo que às penalidades aplicáveis; ao processo penal; à anistia; à criação de novas ordens de jurisdição e ao estatuto dos magistrados; à base, à taxa e às modalidades de arrecadação de impostos de todo o tipo; ao sistema de emissão da 
moeda. " ... "ao regime eleitoral das assembléias parlamentares e das assembléias locais; à criação de categorias de estabelecimentos públicos; às garantias fundamentais concedidas aos funcionários civis e militares do Estado: às nacionalizações de empresas e às transferências da propriedade do setor público ao setor privado.

A lei determina os princípios fundamentais: da organização geral da defesa nacional; da livre administração das coletividades locais, de suas competências e de seus recursos; do ensino; do regime da propriedade, dos direitos reais e das obrigações civis e comerciais; do direito do trabalho, do direito sindical e da previdência social.

As leis orçamentárias determinarão os recursos e os encargos do Estado nas condições e com as reservas estalecidas por uma lei orgânica. Leis de programação determinarão os objetivos da ação econômica e social do Estado.

As disposições do presente artigo poderão ser detalhadas e completadas por uma lei orgânica."

Diante de tais disposições constitucionais, lembra Manoel Gonçalves Ferreira Filho, podem ser visualizados, na França, três tipos de regulamento: o de execução, o de complementação e o autônomo. Escreve: "O primeiro (de execução) não foge à linha clássica. Destina-se a facilitar ou a propiciar a execução das leis. Cabe nas matérias reservadas pelo constituinte à lei, mas somente pode explicar o que nesta seja determinado, sem criar obrigação nova (no fundo). Conserva esse regulamento pois, caráter totalmente subordinado. O segundo (de complementação) visa a editar regras que decorram dos princípios adotados pelo legislador nas matérias em que Ihe cabe apenas traçar as linhas fundamentais. Esse regulamento se subordina aos princípios contidos na lei, mas evidentemente não apenas explicita regras. Substancialmente cria regras dentro de certas linhas afixadas pela lei. Essa forma de regulamento se acha numa zona cinzenta entre a velha e a nova concepção. O terceiro (autônomo) é propriamente a novidade. Ė o regulamento autônomo legalmente incondicionado, expressão do que Vedel chamou de "poder normativo governamental". Por ele o governo edita regras somente subordinadas à Constituição. Em seu campo, que é o geral, pode mesmo alterar ou revogar leis anteriores." (A Autonomia do poder regulamentar na Constituição Francesa de 1958, RDA, 84/24; Do Processo legislativo, Saraiva, 1968 , p. 145 e segs.). Deveria o regulamento autônomo ser encarado como lei ontologicamente? O Conselho de Estado francês o tem entendido como ato de natureza administrativa - no que age com acerto, diante do critério formal de distinção entre lei e regulamento - ao reconhecer "os regulamentos autônomos suscetíveis de impugnação pelo recurso por excesso de poder, da mesma forma que os regulamentos de execução." (Manoel Gonçalves Ferreira Filho, ob. cit., RDA, 84/36). Ensina G. Vedel que o recurso de excesso de poder é recurso administrativo cabivel contra ato de natureza administrativa (Droit administratif, Paris, 1961, p. 389 e segs. ; ap. Manoel Gonçalves Ferreira Filho, Do Proc. legislativo, citado, p. 148). 


\section{A delegação legislativa no sistema constitucional brasileiro}

Poder regulamentar deve ser entendido como atividade de natureza administrativa, inconfundível, pelo menos no sistema constitucional brasileiro, com a técnica de delegação legislativa. A "crise legislativa" determinada por vários fatores, dentre eles a transformação do estado policial, estado parasita (M. Duverger) em estado prestador de serviços, o intervencionismo estatal, a urgência de certas medidas (campo econômico, financeiro, etc.) , a tecnicalidade de certas decisões do Estado-empresa, têm deslocado a legiferação para o âmbito do Poder Executivo. Assim na Constituição da França, de 1958, conforme vimos de ver (artigo 38), na Lei Fundamental da Alemanha Federal (artigo 80), na Constituição italiana de 1948. com a lei delegada (art. 76) e os decretileggiou ordinanze dinecessità. O direito constitucional brasileiro não ignora essa nova tendência do constitucionalismo. A Constituição brasileira adota diversas formas de delegação legislativa, quer acolhendo a participação do Executivo no processo legislativo, pela iniciativa geral das leis larts. 51 e 56), pela iniciativa reservada (C.F., arts. 57, 65 e 66) e pela iniciativa vinculada (C.F., arts. 66, 81, XIX, 82, VI), pela possibilidade de serem fixados prazos dentro nos quais o Legislativo deverá apreciar os projetos de lei encaminhados pelo Presidente da República, sob pena dos projetos de lei serem considerados aprovados por decurso do prazo (C.F., art. 51), quer pela competência conferida ao Presidente da República para a edição de decretos-leis a respeito de determinadas matérias e desde que ocorrentes certas circunstâncias, exigida a aprovação do Congresso (C.F., art. 55), quer pela delegação propriamente dita, - possibilidade de o Presidente da República editar leis delegadas, observadas certas restrições (C. F., artigos 52 a 54).

A delegação não é atentatória ao sistema democrático, desde que esteja o Executivo sujeito a rígido controle por parte dos Poderes Legislativo e Judiciário. Aquele, tornando efetivo o controle político; este, exercitando o controle de constitucionalidade. Se é verdade que, do caráter democrático da separação dos poderes, resulta a proibição de delegação de atribuições de um a outro poder, certo é que, se tal delegação se faz pelo constituinte, desaparece a eiva da ilegitimidade, passando a questão para o domínio da competência, no sentido de que o titular do poder constituinte (o povo) repartiu a competência legiferante entre dois poderes. Essa nova concepção constitucional, ademais, assenta-se em razões de necessidade. Escreveu Charles Hughes que "os princípios que dominam a delegação do poder legislativo são claros. A legislatura não pode delegar os seus poderes para fazer uma lei; mas pode fazer uma lei para delegar um poder com o objetivo de determinar um dado de fato ou um estado de cousas do qual a lei faz ou tem a intenção de fazer depender a sua ação. Contestar isto, seria travar as rodas do governo. Há muitas cousas sobre as quais uma sábia e útil legislação deve repousar e que não podem ser conhecidas do Poder Legislativo; devem, pois, ser buscadas e determinadas fora das Câmaras." (Carlos Maximiliano, Com. Const. Brasileira, I/409; ap. Vicente Ráo, ob. cit., volume I, Tomo II, p. 253). 
Não custa repetir: o que faz ilegítima a delegação legislativa é a falta de controle político, por parte do Congresso, e do controle de constitucionalidade, da parte do Judiciário.

Relembre-se, em conclusão, que as técnicas de delegação legislativa adotadas pela Constituição brasileira de 1967, com a EC n. 1, de 1969 - o decreto-lei (C.F., artigo 55) e a lei delegada (C.F., artigos 52 a 54) - não se confundem com o poder regulamentar. Aquela, é atividade legislativa; este, atividade administrativa.

\section{O regulamento no sistema constitucional brasileiro}

O regulamento de execução - O regulamento, que o sistema constitucional brasileiro admite, é o de execução (C.F., artigo 81, III). Geraldo Ataliba chega a classificar de "ridículo que um brasileiro, tratando da faculdade regulamentar, à luz do nosso direito, abra um tópico" para o regulamento autônomo. Acrescenta o ilustre mestre: "diante de um texto constitucional que prescreve que o regulamento só se justifica para a fiel execução das leis (art. 81, III. 2. parte), mencionar a idéia de regulamento autônomo, neste contexto, é gesto de grande ousadia." "Liberdade e poder regulamentar, Rev. de Informação Legislativa", Senado Federal, 66/45; Decreto regulamentar no sistema brasileiro, RDA, 97/21).

O sistema constitucional brasileiro desconhece, em verdade, a figura do regulamento autônomo, que a Constituição francesa admite. Fomos buscar, aliás, na Constituição da França de 1958, justamente no regulamento autônomo, inspiração para a instituição, na Constituição brasileira de 1967, do decreto-lei (C.F., art. 55). O decreto-lei, todavia, já ficou claro, não se confunde com o decreto regulamentar. No Brasil, o regulamento é simplesmente de execução (C.F., art. 81, III).

Assim, no direito brasileiro o regulamento exige a existência de lei, porque ele nada mais é senão "auxiliar das leis, auxiliar que sói pretender, não raro, o lugar delas, mas sem que possa, com tal desenvoltura, justificar-se, e lograr que o elevem à categoria de lei." (Pontes de Miranda, Comentários à Const. de $1967 \mathrm{com}$ a EC n. 1/69, RT, 2ed., III/314).

O falso regulamento de execuçao e o regulamento "praeter legem" - Certas leis conferem ao Chefe do Poder Executivo a faculdade de, regulamentando-as, inovarem de forma inicial na ordem jurídica. Tem-se, em caso assim, autêntica delegação legislativa. Valeriam esses regulamentos? É claro que não. Ė que a Constituição, no art. $6^{\circ}$, parág. único, proíbe a qualquer dos Poderes delegar atribuições, observadas as exceções previstas na Constituição. Esta, ao proibir a delegação de funções, estabelece, em caráter, excepcional, os casos em que é possível a delegação legislativa. A Constituição, pois, ao proibir a delegação de atribuições, estabelece, em caráter excepcional, os casos em que é possível a delegação legislativa: o Presidente da República pode elaborar leis delegadas, observadas certas restrições (C.F., arts. 52 a 54). Pode, outrossim, em certas matérias e sob determinadas condições, legislar através 
de decreto-lei (C.F., art. 55). Não pode o Presidente da República, entretanto, legislar via de decreto-regulamentar, por isso que o regulamento, no Brasil, é ato normativo secundário, que não pode inovar, na ordem jurídica, porque só pode ser expedido para fiel execução da lei (Michel Temer, Elementos de dir. const., R. T., 1982, p. 178e segs.).

Também não tem guarida, no direito brasileiro, o regulamento praeter legem, que é o editado para preencher o espaço vazio da lei, também chamado de regulamento independente, que cede, todavia, diante da lei. Laborando no vazio, inova na ordem jurídica, impondo obrigações e estabelecendo limitações à liberdade individual, não previstas em lei. Destarte, " por aplicação estrita do princípio da legalidade, deveriam ser rejeitados por inconstitucionalidade." (Manoel Gonçalves Ferreira Filho, Do Proc. legisl., citado, p. 135). E nesse caso seriam mesmo inconstitucionais, interferindo na questão, além do art. 153, § 2. , o art 81, III, da Constituição. Inconstitucionais, sujeitos ao controle de constitucionalidade, no caso de não existir lei que os preceda. Porque, existindo lei, ultrapassando o regulamento a lei, o caso é de ilegalidade. Com notável precisão lecionou, no Supremo Tribunal Federal, o Ministro Décio Miranda: "Sempre entendi que o regulamento contrário à lei é ilegal, não sendo necessário declarar que é inconstitucional. É verdade que às vezes se tem declarado a inconstitucionalidade de regulamentos, mas não porque ofendam a lei - é que, sem lei nenhuma que os preceda, ofendem a Constituição." (Voto no RE n. 93 545-SP, RTJ, 99/1366).

Pela legitimidade do regulamento praeter legem, ou regulamento independente, opina o douto Hely Lopes Meirelles, o qual, não obstante deixar expresso que o regulamento é ato inferior à lei, pelo que "não pode contrariar, nem restringir ou ampliar suas disposições", sustenta: "na omissão da lei o regulamento supre a lacuna, até que o legislador complete os claros da legislação. Enquanto não o fizer, vige o regulamento, desde que não invada matéria reservada à lei" . (Dir. administrativo brasileiro, RT, 8. ed., 1981, p. 106). Com a venia devida, divirjo do entendimento do ilustre administrativista, porque, não custa repetir, a Constituição lart. $6^{\circ}$, parág. único; art. 81, III; art. 153, § 2.) impede que o "Executivo estabeleça, por fora ou para além das leis, direitos ou muito menos obrigações aos indivíduos", certo que "nenhuma restrição à liberdade ou à propriedade pode ser imposta se não estiver previamente delineada, configurada e estabelecida em alguma lei" . (Celso Antônio Bandeira de Mello, Ato administrativo e direito dos administrados, RT, São Paulo, 1981, p. 85/86).

O regulamento delegado ou autorizado, intra legem - Já o regulamento delegado ou autorizado (ver acima) , intra legem, é admitido pelo direito constitucional brasileiro, claro, porém, que não podem "ser elaborados praeter legem, porquanto o seu campo de ação ficou restrito à simples execução de lei." (O. A. Bandeira de Mello, ob. cit., I/354; Celso Bastos, Curso de Dir. Const., Saraiva, 3 ed., 1980, p. 177).

Votando no Supremo Tribunal Federal, o Ministro Aliomar Ba- 
leeiro traçou os contornos desse regulamento, exatamente como admitido pelo direito brasileiro: se a lei fixa exigências taxativas, é exorbitante o regulamento que estabelece outras, como é exorbitante o regulamento que faz exigência que não se contém nas condições exigidas pela lei. Mas, acrescentou o Ministro Baleeiro: "Meu voto confirmaria o V. Acórdão se a L. 4.862 expressamente autorizasse o regulamento a estabelecer condições outras, além das que ela estatuir. Aí, não seria delegação proibida de atribuicões, mas flexibilidade na fixação de standards jurídicos de caráter técnico, a que se refere Stati." (REn. 76 629-RS, RTJ, 71/477).

Esse é, aliás, o tipo de regulamento que a Corte Suprema americana tem permitido, sem embargo de consagrar a Constituição dos Estados Unidos, de 1787, a separação dos poderes e estabelecer, expressamente, no seu artigo 10. Sec. I, que "All legislative powers herein granted shall be vested in a Congress of the United States, which shall consist of a Senate and House of Representatives." (Todos os poderes legislativos conferidos por esta Constituição serão confiados a um Congresso dos Estados Unidos, composto de um Senado e de uma Câmara de Representantes). É que, como anota Bernard Schwartz, "segundo a atual teoria americana, o poder legislativo pode ser conferido ao ramo executivo, desde que a outorga de autoridade seja limitada por determinados padrões." (Direito const. americano, Forense, tradução de Carlos Nayfeld, p. 350). Em "United States v. Chicago, M., St. P. and P.R.R., 282 U.S. 311, $324(1931)$ ", a suprema Corte decidiu que "o Congresso não pode delegar qualquer parte de seu poder legislativo exceto sob a limitação de um padrão estabelecido." (Ap. B. Schwartz, ob. e loc. cits.) . Acrescenta Schwartz: "O arbítrio conferido não pode ser tão amplo que se torne impossível discernir os seus limites. Outrossim, precisa haver certa intenção legislativa com a qual se deve harmonizar o exercício do poder delegado" (ob. e loc. cits), certo que, "a menos que o ato de delegação de poderes contenha um padrão - limite ou orientação com respeito ao poder conferido que se possa exercer - ele será inválido ou nulo." (ob. cit., p. 34).

Em voto proferido no Tribunal Federal de Recursos, o Ministro Armando Rollemberg, em tema de imposto de renda, expressou a melhor doutrina e manteve decreto regulamentar que mandava excluir as provisões do capital invertido, por isso que, ao assim proceder, o regulamento não contrariou a lei regulamentada, mas apenas explicitou-a. Vale a transcrição do voto, para se verificar como o eminente Ministro soube distinguir a delegação do poder de legislar, que é probida, "da autorização para completar os contornos da lei, desenvolvendo-a dentro de órbita circunscrita". (O. A. Bandeira de Mello, ob. cit., I/346-347). Escreveu o Ministro Rollemberg: "Examinei, tendo em conta tais princípios, a regra do art. 44 do D. 24.239, de 1947, e, sem embargo dos fundamentos do voto vencido e das lúcidas razões do procurador da embargante, não me conveci de que ali houvesse exorbitância da regulamentação da L. 154, do mesmo ano. Esta, ao fixar o critério para o pagamento do imposto de renda pelas empresas concessionárias de serviço público, utilizou como elemento o capital invertido para a obtenção do lucro, de cujo cômputo o regulamento excluiu as provisões. O que se há de 
indagar, portanto, é se tal exclusão é contrária à lei, ou se, ao invés disso, estava implícita na norma legal, o que afinal importa em perquirir se as provisões são ou não utilizadas pelas empresas para a obtenção de lucro.

A resposta há de ser buscada no exame da natureza das provisões. Que são elas afinal? São fundos "destinados a amparar situações indecisas ou pendentes, que passam de um exercício para outro", di-lo Miranda Valverde (Soc. por ações, II, n. 676), que "correspondem à existência de um risco efetivo, de sorte que sua inscrição no balanço corresponde a uma necessidade" , afirmam Hamele Lagarde (Traité de droit commerciele, ed. 1954, I, n. 722). Destinam-se a fazer face a perdas e encargos eventuais comprovados, esclarecem Maurice Duverger (Finances publiques, 5. ed., 533) e Louis Trotabas (Finances publiques, ed. 1964, p. 408).

Ora, se as provisões têm por finalidade acudir perdas e encargos eventuais ou prováveis, as importâncias respectivas hão de estar sempre, senão em caixa, empregadas em títulos de pronta realização, e, conseqüentemente, não são investidas no negócio para obtenção delucros.

É inafastável, a meu ver, assim, a conclusão de que o regulamento, ao excluir as provisões do capital invertido pelas empresas concessionárias para obtenção de lucro, não alterou a lei e sim explicitou-a, dando à expressão o seu real alcance." (In voto do Ministro Xavier de Albuquerque no REn. 74.589-SP, RTJ, 64/500).

Esse voto foi acolhido pelo Supremo Tribunal Federal, no RE n: 74.589-SP, Relator o Ministro Xavier de Albuquerque (RTJ, 64/500).

Já no Agravo de Instrumento n: 51.085 - (AgReg) - GB Relator o Ministro Barros Monteiro, a Corte Suprema liqüidou com o regulamento que, extravasando a legislação regulamentada, extinguiu benefícios cuja concessão era prevista em lei.

É que, conforme leciona Celso Antônio Bandeira de Mello, “o regulamento mais não poderá fazer além de expedir comandos intra legem, pois nem contra, nem extra, nem praeter, nem ultra legem caber-lhe-á introduzir qualquer determinação. Sobretudo, no direito brasileiro - ante os preceptivos reiteradamente citados - é evidente tal limitação." (Ato administ. e dir. dos administrados, RT, 1981, p. 90).

\section{Leis que dependem de regulamento}

Leis administrativas - Esclareça-se, primeiro que tudo, que "só as leis administrativas comportam regulamentação. A Constituição não consente que se regulamente lei não administrativa", lembra Geraldo Ataliba (Liberdade e poder regulamentar, Rev. de Inf. Leg., 66/45. É que, "em rigor, a matéria do regulamento, seu objeto é a disciplina das situações em que cabe discricionariedade administrativa no cumprimento da lei, da qual resultariam diferentes comportamentos administrativos possíveis." (Celso Antônio Bandeira de Mello, ob. cit. , p. 91). Impossível, pois, regulamentação das 
leis civis, processuais, comerciais, trabalhistas, penais, etc., acrescenta Ataliba (ob. cit.), na linha, aliás, do entendimento de Celso Bastos: "Fundados na atividade administrativa, os regulamentos são atos voltados à ordenação da própria máquina burocrática da Administração. Obrigam também, sem dúvida, aos próprios particulares, a quem criam obrigações acessórias e conferem direitos subjetivos. Pressupõem, sempre, entretanto, uma atividade conjunta da Administração e do particular, cuja atuação visam a harmonizar. Dai ser impossível a regulamentação de leis como o Código Civil, Penal, etc., que não envolvem qualquer participação da Administração no cumprimento de suas normas." (Curso de dir. constituc., Saraiva, 3 ed., 1980, pág. 177).

Leis auto-executáveis e não auto-executáveis - Isto esclarecido, já nos é possível anotar as leis que dependem de regulamentacão para serem aplicadas, ou, noutras palavras, estabelecer os lindes das leis auto-executáveis das leis não auto-executáveis. Não são auto-executáveis, pelo que dependem de regulamentação, aquelas que expressamente declaram que devem ser regulamentadas. Segundo Hely Lopes Meirelles, essas leis "não são exequíveis antes da expedição do decreto regulamentar, porque esse ato é conditio juris da atuação normativa da lei. Em tal caso, o regulamento opera como condição suspensiva da execução da norma legal, deixando os seus efeitos pendentes até a expedição do ato do Executivo. "Todavia, se a lei fixa prazo para a expedição do regulamento, se este não é editado no prazo, "os destinatários da norma legislativa podem invocar utilmente os seus preceitos e auferir todas as vantagens dela decorrentes, desde que possa prescindir do regulamento, porque a omissão do Executivo não tem o condão de invalidar os mandamentos legais do Legislativo." (Hely Lopes Mirelles, Dir. adm. bras., 8 ed., RT 1981, p. 106-107), No mesmo sentido O. A. Bandeira de Mello (ob. cit., 1/361-362).

Convém lembrar que há leis que dependem de regulamentação apenas em parte. A parte auto-executável, não dependente de regulamentação, tem eficácia a partir da vigência da lei (O. A. Bandeira de Mello, ob. cit., 1/361).

Em suma, o regulamento pressupõe uma lei, uma lei que comporte regulamentação, assim uma lei administrativa, ou cuja execução caiba ao Chefe do Executivo (Presidente da República, Governador, Prefeito Municipal), não auto-executável, por isso que nela claramente ficou expresso que deveria ser regulamentada. Se nessa declaração ficou explícito que o regulamento deveria ser expedido dentro num certo prazo, vencido este, sem a expedição do regulamento, a lei passa a ter eficácia, desde que possa prescindir do regulamento. Se a lei não fixar prazo para a sua regulamentação, a sua eficácia fica na dependência do regulamento, porque este, em caso assim, é conditio juris da atuação normativa da lei. 